\title{
Asymmetric effects of geopolitical risks on Turkey's tourist arrivals
}

\author{
Ender Demir \\ Istanbul Medeniyet University \\ Faculty of Tourism \\ Istanbul, Turkey \\ E-mail: ender.demir@medeniyet.edu.tr \\ Serdar Simonyan \\ Universidad Carlos III de Madrid, Spain \\ Email: 100359367@alumnos.uc3m.es
}

\author{
Ming-Hsiang Chen \\ Corresponding Author \\ School of Recreational Sports and Tourism \\ Beijing Sport University \\ Beijing 100084, China \\ School of Hospitality Business Management \\ Carson College of Business \\ Washington State University \\ Pullman, WA 99164-4742, USA \\ Tel.: 509-335-2317 \\ E-mail: ming-hsiang.chen@,wsu.edu \\ and \\ Tourism and Social Administration College \\ Nanjing Xiaozhuang University \\ Nanjing 211171, China
}

Chi Keung Marco Lau

Department of Accounting, Finance and Economics

Huddersfield Business School

University of Huddersfield, Huddersfield, the United Kingdom

C.Lau@hud.ac.uk 


\begin{abstract}
This paper applies Nonlinear Autoregressive Distributed Lag model to examine the effects of geopolitical risks (GPRs) on Turkey's tourist arrivals (TAs) from January 1990 to December 2018. The newly developed Geopolitical Risk Index (GPRI) is used to measure GPRs. Test results reveal interesting findings. While the effects of GPRs on TAs are expected, the effects are found to be asymmetric in the short-run. Specifically, an increase in GPRI reduces TAs in Turkey, but a decrease in GPRI has no effect in the short-run. Moreover, there is no evidence for such an asymmetry in the long-run.
\end{abstract}

Keywords: Geopolitical risks; Turkey; Tourist arrivals; Nonlinear Autoregressive Distributed Lag model 


\section{Introduction}

Tourism plays an important role in driving economic development of emerging countries. However those countries face severe risks such as conflicts, political instabilities, security issues, and terror. When geopolitical risks (GPRs) increase in a country, personal security concerns will lead to postponement or cancellation of travel plans. Travelers will be reluctant to visit a country experiencing a rise in GPRs due to their safety issue. Consequently, this will decrease tourist arrivals (TAs).

This study aims to examine the impact of GPRs on TAs to Turkey. Turkey has experienced several events such as the rising tension between Syria and Turkey in October 2012, Gezi Park protests in May 2013, Turkey's downing of Russian warplane in November 2015, the failed coup attempt in July 2016, Turkey's Operation Olive Branch in January 2018 which increased the GPRs (see Figure 1).

\section{(Figure 1 here)}

Caldara and Iacoviello (2018) develop the Geopolitical Risk Index (GPRI) based on the automated text-searches of newspapers. Since its introduction, there is a rising interest of the literature to use GPRI as a proxy for geopolitical risks. Demir et al. (2019) is the first using examining the effect of this newly developed GPRI on tourism demand. By using a panel-data of 18 countries, it is found that an increase in geopolitical risks leads to a decrease in inbound tourist arrivals. In a similar vein, Balli et al. (2019) show that GPRs negatively affect tourism demand, but this effect is found to be heterogeneous, meaning that some countries are more affected from GPRs while some are immune to GPRs shocks.

Tiwari et al. (2019) compare the effects of GPRs and Economic Policy Uncertainty (EPU) on tourist arrivals. It is found that the impact of geopolitical risks is stronger than that of economic policy uncertainties. In terms of stock market effects, Demiralay and Kilincarslan (2019) examine the impact of GPRs on the Travel and Leisure industry stock 
indices. They document the negative effect of GPRs on T\&L stock index returns except for Asia \&Pacific. This effect is asymmetric, with a significant effect in lower quantiles. Saint Akadiri et al. (2020) find that there is a unidirectional causality running from GPRs to economic growth and from GPR to tourism growth.

While the previous studies mainly focus on the linear (symmetric) relationship between several variables such as oil prices, uncertainty, exchange rates on tourism demand, this study investigates whether the effects of GPRs on Turkey's TAs are asymmetric. There is a scarce literature on the asymmetric effects of those variables on tourism. Al-Mulali et al. (2019) reveal that increases in oil prices have a stronger impact on TAs than decreases in oil prices in Malaysia. Falk and Lin (2018) find that an increase in winter temperatures causes a decrease in the number of winter TAs while temperature decreases have no effect on TAs in Italy.

The major contribution of this study is to apply the Nonlinear Autoregressive Distributed Lag (NARDL) approach to examine the asymmetric effects of GPRs on TAs. The NARDL model can capture the asymmetric effects in the short-run and long-run relationships between variables. Particularly, the NARDL model allows two separate coefficients (decreases or increases) to measure the effects of GPR on TAs.

\section{Data and variables}

All sample monthly data used in the study are from January 1990 to December 2018. The dependent variable is the number of inbound TAs to Turkey. The independent variable is Geopolitical Risk Index (GPRI) developed by Caldara and Iacoviello (2018) to measure GPRs for 18 emerging economies. Geopolitical risk is defined as "the risk associated with wars, terrorist acts, and tensions between states that affect the normal and peaceful course of international relations" (Caldara and Iacoviello, 2018 p.6). GPRI is calculated by dividing the total number of articles about GPRs in each newspaper to the total number of news articles, 
on a monthly basis. This process is performed by running automated text-searches of 11 newspapers. The construction of the index organized in six categories, namely "Geopolitical Threats, Nuclear Threats, War Threats, Terrorist Threats, War Acts, and Terrorist Acts". The first four of categories are related to geopolitical threats and tensions, while the last two are on geopolitical events and acts. ${ }^{1}$ This index aims to measure an important dimension of uncertainty, which is the risk of events that hinder the normal, democratic, and peaceful course of relations across countries and societies.

The study also uses inflation and oil price as control variables. Consumer price index is used as a proxy to measure the impact of inflation and crude oil price series are chosen to observe the effect of oil price. The data series are obtained from Federal Reserve Bank of St. Louis (FRED). As seasonality component is an important aspect of tourism in terms of employment and capital investment, we seasonally adjust our series by applying X-12ARIMA filter in Eviews.

\section{Methodology}

The NARDL framework is useful to study the impact of an explanatory variable on dependent variable both in the long-run and in the short-run. To detect whether the impact of GPR on inbound tourism is asymmetric, the GPRI is decomposed into increases and decreases as the following:

$$
G P R I_{t}^{+}=\sum_{t=1}^{T} \Delta G P R I_{t}^{+}=\sum_{t=1}^{T} \max \left(\Delta G P R I_{t}, 0\right),
$$

and

$$
G P R I_{t}^{-}=\sum_{t=1}^{T} \Delta G P R I_{t}^{-}=\sum_{t=1}^{T} \min \left(\Delta G P R I_{t}, 0\right)
$$

\footnotetext{
${ }^{1}$ The GPRI data were downloaded from the website of Caldara and Iacoviello (see https://www2.bc.edu/matteoiacoviello/gpr.htm for more details about the construction of index).
} 
where $\triangle G P R I$ represents changes in the GPRI. The model that we establish for inbound tourism is as follows.

$$
\begin{aligned}
& \Delta I T_{t}= \sigma_{1}+\gamma I T_{t-1}+\varphi_{1} G P R I_{t-1}{ }^{+}+\varphi_{2} G_{P R I_{t-1}}{ }^{-}+\varphi_{3} C P I_{t-1}+ \\
& \varphi_{4} O I L_{\mathrm{t}-1}+\sum_{i=0}^{j} \gamma_{i} \Delta O I L_{t-i}+\sum_{i=0}^{k} \gamma_{i} \Delta C P I_{t-i}+ \\
& \sum_{i=1}^{l} \gamma_{i} \Delta I T_{t-i}+\sum_{i=0}^{m}\left(\Pi_{i}{ }^{+} \Delta G P R I^{+}{ }_{t-i}+\Pi_{i}{ }^{-} \Delta G P R I_{t-i}{ }^{-}\right),
\end{aligned}
$$

where IT denotes the monthly TAs, CPI is consumer price index, and OIL is crude oil price. ${ }^{2}$ All the variables are in natural logarithms. The equality $\Pi_{i}^{+}=\Pi_{i}^{-}$is tested to see if an asymmetry exists in the short-run. If the equality is rejected, it indicates that there is an asymmetric impact.

For the case of long-run, the equality of $\varphi_{1}=\varphi_{2}$ should be examined. We apply NARDL bounds test approach to determine whether there is cointegration. The only restriction to apply this approach is that, no variable should be integrated more than order one. We use Augmented Dickey Fuller (ADF) test to check whether all variables are eligible to be present in the model. The ADF test results show that all variables, except GPRI, are found to be I(1), meaning that a differentiation of these variables will generate stationary series. GPRI variable is found to be $\mathrm{I}(0)$, which is originally stationary. After meeting the specification for integration, we continue with the determination of cointegration. The null hypothesis and alternative hypothesis is as follows.

versus

$$
H_{0}: \gamma=\varphi_{1}=\varphi_{2}=\varphi_{3}=\varphi_{4}=0
$$

$$
H_{1}: \gamma \neq \varphi_{1} \neq \varphi_{2} \neq \varphi_{3} \neq \varphi_{4} \neq 0 \text {. }
$$

There exists two tests for this exercise: BDM t-statistic $\left(t_{B D M}\right)$ and PSS F-statistic $\left(F_{P S S}\right)$. Two critical values are identified for these tests by Pesaran et al. (2001): upper bound and lower bound. Here, there exists a cointegration, if the test result is above the upper

\footnotetext{
${ }^{2}$ Due to the high correlation between CPI and Exchange Rate (USD / TL), only CPI variable is included in the estimations.
} 
bound. No evidence of a cointegration exists if the result is below the lower bound, or that if it falls between the boundaries. Akaike Information Criterion (AIC) is used to choose optimal lag length. The automatic lag selection of the AIC criteria provides us NARDL $(1,0,0,1,0)$ as the model which creates least errors.

\section{Test results and discussion}

Before conducting the nonlinear version of ARDL estimation, we have to confirm the existence of long run relationship between inbound tourism and explanatory variables, therefore we begin our analysis with the $\mathrm{F}$ bounds test of $t_{B D M}$ and $F_{P S S}$ cointegration test statistics (see Table 1). In both tests, the obtained result is greater than the upper bound, suggesting that there is cointegration between inbound tourism and explanatory variables used. After we identify cointegration in our model, we continue with the results of the established model, which is presented in Table 2. It is observed that the GPR has a negative sign both in the long-run and in the short-run, as expected.

\section{(Tables 1-2 here)}

For the case of short-run, there is an evidence for the asymmetric effect. The increases in GPRs are statistically significant while the decreases are not found to be statistically significant. This implies that an increase in the GPR will lead to a decline in TAs, while a decrease in the GPR have no significant effect on the number of tourists in the short-run. Sharma (2020) shows that economic uncertainty has asymmetric effects on tourism demand in India. In this regard, our finding supports the asymmetric effect of another dimension of uncertainty namely geopolitical risk. However, Sharma (2020) finds that the negative effect of the increasing uncertainty is stronger than the positive effect of the decreasing uncertainty. We document that only increases in the geopolitical risks matter for tourist arrivals to Turkey. 
It is also found that both increases and decreases of GPR are statistically significant to explain TAs in the long-run, meaning that an increase in GPR decreases the demand for tourism and vice versa. However, the asymmetry condition cannot be rejected, indicating that the decreases and increases have the same effect on TAs in the long-run. ${ }^{3}$ Our finding for the case of long-run is in line with the Demir et al. (2019) and Balli et al. (2019) which document the negative effect of GPRs on tourism demand.

The asymmetric dynamic multiplier (see Figure 2) provides useful information about the reaction of TAs to a unit shock in GPRI. It illustrates that $1 \%$ increase in GPRI decreases the demand for tourism and vice versa. However, the magnitude of impact on TAs is not the same, showing that an increase in GPRI depresses the demand for tourism more than it stimulates when a decrease in GPRI is occurred. The coefficient of oil prices is positive at time $t$ while it turns to negative at time $t-1$ in the short-run. In the long-run oil prices have a positive effect on tourist arrivals to Turkey. Moreover, we also find that an increase in CPI decreases the number of tourist arrivals in the short-run.

\section{(Figure 2 here)}

In addition, we also test the linear ARDL model. Test results reveal that the coefficient of GPRI in the model is negative, implying that an increase (decrease) in GPRI leads to a decrease (increase) in tourist arrivals to Turkey. ${ }^{43}$ However, the impact of GPRs on inbound tourism may exhibit asymmetric behavior. Therefore, we implement the asymmetric test for nonlinear causality of Hristu-Varsakelis and Kyrtsou (2008) to analyze whether there is as symmetric or asymmetric nonlinear causality from GPR to tourist arrivals. The results in Table 3 shows that there is no evidence of symmetric nonlinear causality from GPRI to

\footnotetext{
${ }^{3}$ For robustness check, we estimate a regression with asymmetric dynamics for all independent variables, and there is no evidence of heteroscedasticity in the residuals using Breusch/Pagan heteroskedasticity test. The GPR related coefficient are similar to those in Table 2.

${ }^{4}$ Results are available upon request.
} 
tourist arrivals. Further asymmetric nonlinear causality test documents that positive GPRs cause tourist arrivals while negative GPR does not causes tourist arrivals.

\section{Implication and conclusion}

This paper applies the NARDL model to examine the asymmetric effects of GPRI on Turkey's TAs from January 1990 to December 2018. Test results reveal interesting findings. While the effects of GPRs on TAs are expected, the effects are found to be asymmetric in the short-run. Specifically, an increase in GPRI reduces TAs to Turkey, but a decrease in GPRI has no effect in the short-run. Moreover, there is no evidence for such an asymmetry in the long-run.

Asymmetric effects can be expected as increases in GPRs lead to higher public attention and have widespread media coverage globally, especially in the short-run. Such increases are likely to negatively affect TAs in the short-term. On the contrary, decreases in GPRs may not be considered newsworthy and hence would take a longer time period to observe the positive effects of decreasing GPRs on tourism.

The finding of the asymmetric impact of GPRs on tourism has important policy implications. Given that Turkey is prone to GPRs due to both domestic and regional developments, the national government and hospitality/tourism business managers should closely watch the developments of GPRs and take the necessary actions to avoid or eliminate any potential increase in the GPRs as the negative effects can be immediately observed on TAs.

The government should take proactive strategies to mitigate the possible negative effects of GPRs in the short-run. However, the development of GPRs is often beyond the control of policymakers (for example a war or a conflict in a neighborhood country) and thus policymakers would need a good communication strategy with the stakeholders in the 
tourism markets. Moreover, Demir et al. (2019) show that the cash holdings of hospitality companies rise as GPRI increases in emerging economies. Therefore, when GPRI is expected to increase, hospitality/tourism business managers in Turkey could hold excess cash to meet their ongoing financial costs or loss due to the risk of declining tourist inflows in the short run. 


\section{References}

Al-Mulali, U., Gholipour, H.F., \& Al-hajj, E. (2019). The nonlinear effects of oil prices on tourism arrivals in Malaysia. Current Issues in Tourism, forthcoming.

Balli, F., Uddin, G.S., \& Shahzad, S.J.H., 2019. Geopolitical risk and tourism demand in emerging economies. Tourism Economics, forthcoming

Caldara D., \& Iacoviello M. (2018). Measuring geopolitical risk. Board of Governors of the Federal Reserve Board, working Paper.

Demiralay, S., \& Kilincarslan, E. (2019). The impact of geopolitical risks on travel and leisure stocks. Tourism Management, 75, 460-476.

Demir, E., Díez-Esteban, J.M., \& García-Gómez, C.D. (2019). The impact of geopolitical risks on cash holdings of hospitality companies: Evidence from emerging countries. Journal of Hospitality and Tourism Management, 39, 166-174.

Demir, E., Gozgor, G., \& Paramati, S.R. (2019). Do geopolitical risks matter for inbound tourism?. Eurasian Business Review, 9(2), 183-191.

Falk, M. \& Lin, X. (2018). Sensitivity of winter tourism to temperature increases over the last decades. Economic Modelling, 71, 174-183.

Hristu-Varsakelis, D., \& Kyrtsou, C. (2008). Evidence for nonlinear asymmetric causality in us inflation, metal, and stock returns. Discrete Dynamics in Nature and Society, 2008.

Karimi, M.S. (2018). The linkage between tourism development and economic growth in Malaysia: A nonlinear approach. International Economic Journal, 32(1), pp.53-65.

Pesaran, M.H., Shin, Y., \& Smith, R.J. (2001). Bounds testing approaches to the analysis of level relationships. Journal of Applied Econometrics, 16(3), 289-326.

Saint Akadiri, S., Eluwole, K.K., Akadiri, A.C., \& Avci, T. (2020). Does causality between geopolitical risk, tourism and economic growth matter? Evidence from Turkey. Journal of Hospitality and Tourism Management., forthcoming. 
Sharma, C. (2020). Testing the asymmetric effects of the economic policy uncertainty on the tourism demand in India. Tourism Economics, forthcoming

Tiwari, A.K., Das, D., \& Dutta, A. (2019). Geopolitical risk, economic policy uncertainty and tourist arrivals: Evidence from a developing country. Tourism Management, 75, 323327. 


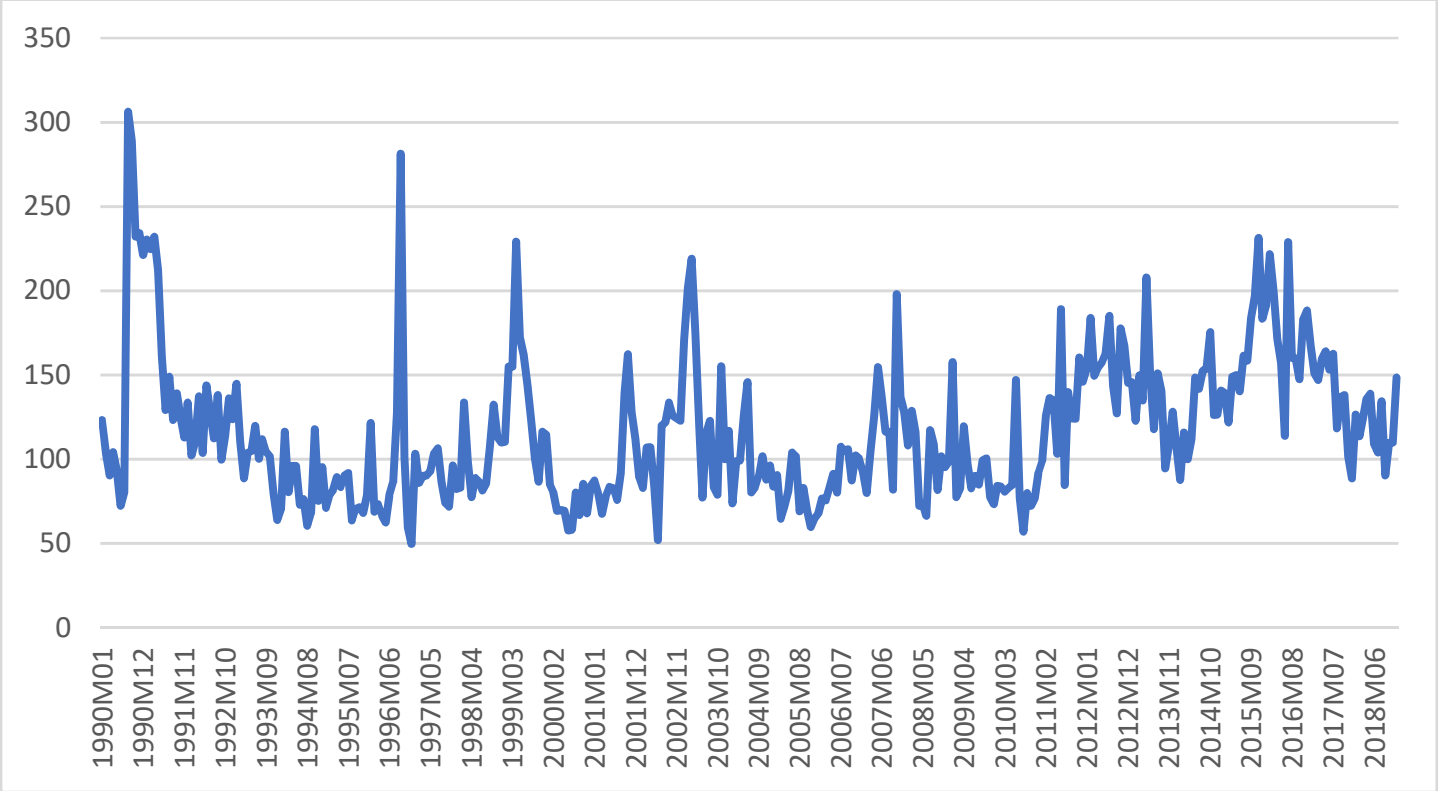

Figure 1. Geopolitical Risk Index of Turkey

Source: Caldara and Iacoviello (2018) 


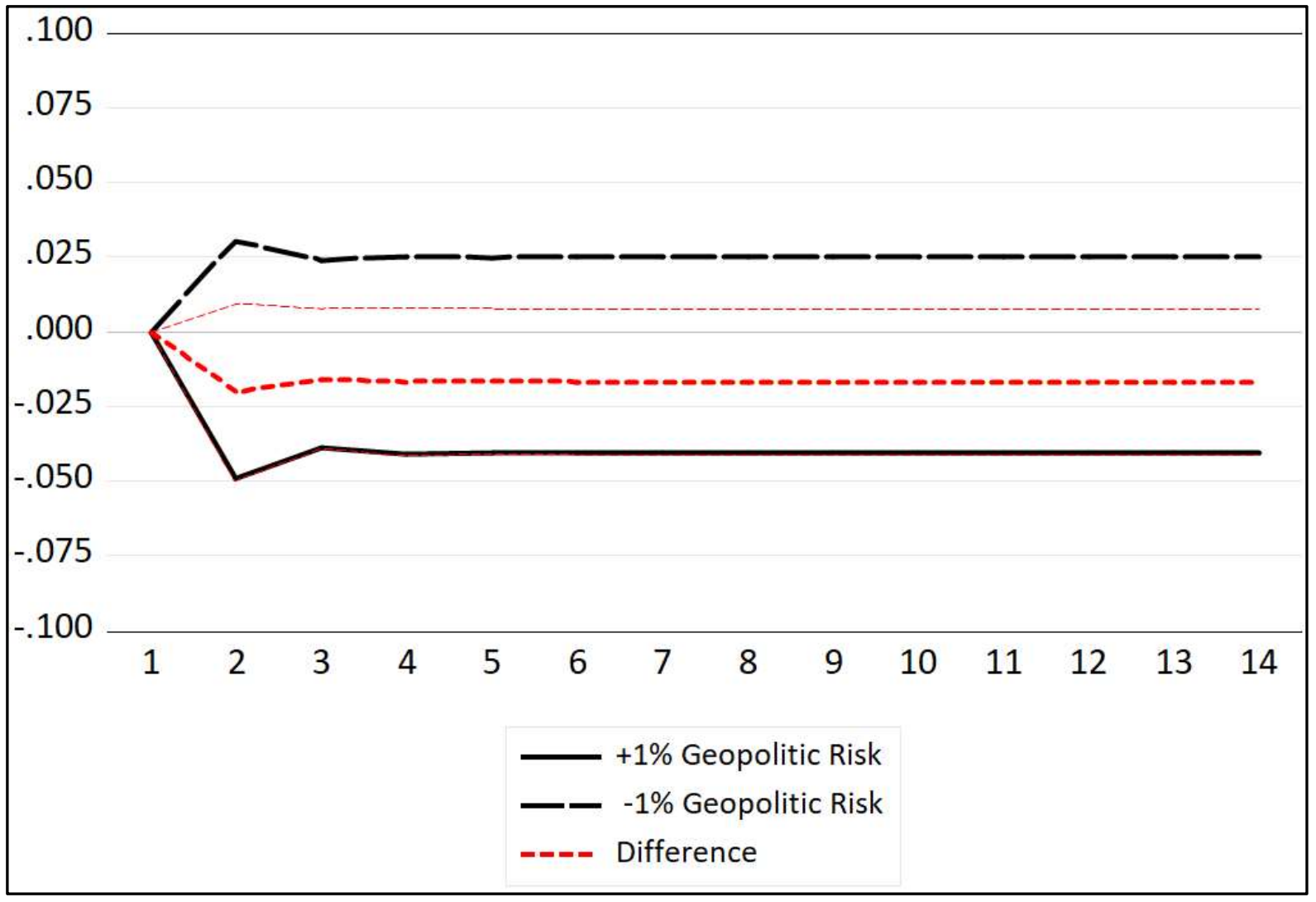

Figure 2. Asymmetric Dynamic Multiplier

Note: $1 \%$ increase in geopolitical risk is shown by black line, whereas $1 \%$ decrease is shown by dashed black line. The dashed red line shows the overall asymmetric impact with dotted red lines being $5 \%$ confidence interval. 
Table 1. Bounds cointegration test

\begin{tabular}{ccc}
\hline & T $_{\text {BDM }}$ & FPSS \\
\hline GPRI & $-7.04^{* * *}$ & $10.21^{* * *}$ \\
\hline
\end{tabular}

Note: ${ }^{* * *}$ indicates significance at $1 \%$ level. $\mathrm{F}_{\text {PSS }}$ test the critical values are 2.26 and 3.35, 2.62 and $3.79,3.41$ and 4.68 for $10 \%, 5 \%$ and $1 \%$, respectively. For $\mathrm{T}_{\mathrm{BDM}}$ test, the critical values are -2.57 and $-3.86,-2.86$ and $-4.19,-3.43$ and -4.79 for $10 \%, 5 \%$ and $1 \%$, respectively. 
Table 2. Nonlinear ARDL estimation results

\begin{tabular}{ccc}
\hline Variables & Coefficient & Standard error \\
\hline$I T_{t-1}$ & $-0.26^{* * *}$ & $(0.04)$ \\
$\Delta \mathrm{GPRI}_{\mathrm{t}}^{+}$ & $-0.05^{* *}$ & $(0.02)$ \\
$\Delta \mathrm{GPRI}_{\mathrm{t}}^{-}$ & $\mathrm{N} . \mathrm{S}$ & N.S. \\
$\Delta O I L_{t}$ & $0.08^{*}$ & $(0.05)$ \\
$\Delta O I L_{t-1}$ & $-0.09^{*}$ & $(0.05)$ \\
$\Delta C P I_{t}$ & $-0.70^{* *}$ & $(0.36)$ \\
$O I L_{t-1}$ & $0.05^{* * *}$ & $(0.02)$ \\
$G P R I_{t-1}^{+}$ & $-0.05^{* *}$ & $(0.02)$ \\
$G P R I_{t-1}^{-}$ & $-0.10^{* * *}$ & $(0.02)$ \\
\hline$\chi_{H E T}^{2}$ & 55.50 & {$[0.000]$} \\
$\chi_{S E R}^{2}$ & 0.02 & {$[0.962]$} \\
$R^{2}$ & 0.28 & \\
\hline
\end{tabular}

Note: The superscript "+" and "-" denote positive and negative cumulative sums, respectively. N.S. indicates the insignificancy of the variable. Heteroskedasticity consistent standard errors are used. Value in bracket are $p$-values. ${ }^{*},{ }^{* *},{ }^{* * *}$ indicate significance at $10 \%, 5 \%$ and $1 \%$ level, respectively. 
Table 3. Test for nonlinear causality

\begin{tabular}{llll}
\hline Relation $(\mathrm{A}=>\mathrm{B})$ & $F$-statistics & $p$-value \\
\hline $\mathrm{GPR}=>$ TA & Symmetric case & 1.5600 & 0.2125 \\
$\mathrm{GPR}=>$ TA & Asymmetric case for positive GPR & 4.5782 & 0.0331 \\
$\mathrm{GPR}=>$ TA & Asymmetric case for negative GPR & 0.4101 & 0.5224 \\
\hline
\end{tabular}

Note: If $p$-value $<0.05$, it indicates the null hypothesis that A does not cause $\mathrm{B}$ is rejected at the $5 \%$ significance level. 